\title{
Effect of UV Irradiation on The Structure of Heterophasic Ethylene-Propylene Copolymers ${ }^{\dagger}$
}

\author{
R. Mani, R. P. Singh, S. Sivaram, and J. Lacoste* \\ Division of Polymer Chemistry, National Chemical Laboratory, \\ Pune-411 008, India \\ * Laboratoire de Photochimie, Universite Blaise Pascal, Clermont-Ferrand II, \\ 63177 Aubiere Cedex, France
}

(Received January 10, 1994)

\begin{abstract}
Changes in $[\eta]$ and crystallinity of commercial samples of isotactic polypropylene (i-PP), heterophasic ethylene-propylene copolymers [E-P copolymer] containing $<16 \mathrm{~mol} \%$ of ethylene and their fractions (having ethylene content 40.9 and $55.7 \mathrm{~mol} \%$ ) upon polychromatic irradiation in air at $55^{\circ} \mathrm{C}$ were studied by comparing unirradiated samples. Crystallinity was evaluated by DSC and X-ray diffraction. Viscosity results showed a decrease of molecular weight upon irradiation. DSC and X-ray studies revealed that the transition of $\alpha$-modification to $\beta$-phase of polypropylene and also that crystallinity of the copolymer decreased initially upon irradiation. However, upon longer irradiation, the crystallinity increased again.

KEY WORDS Ethylene-Propylene Copolymer / Crystallinity / UV Irradiation / Intrinsic Viscosity / DSC / X-Ray Diffraction /
\end{abstract}

Copolymers of propylene with ethylene have assumed increasing significance in recent years. Depending on the method of ethylene incorporation, copolymers can have a range of useful properties, from stiff thermoplastics to soft elastomers.

Literature reports the effects of thermal/ photo-oxidative degradation of this elastomeric copolymers on mechanical properties. ${ }^{1}$ The effect of irradiation on polymers is bondscission resulting in the formation of freeradicals which migrate along the chain. ${ }^{2,3}$ However, the probability of radical combination is dependent on polymer morphology, especially for crystalline and semicrystalline polymers. ${ }^{4}$ Although photooxidative degradation of elastomeric ethylene-propylene copolymers has been the subject of several studies, ${ }^{5-7}$ little attention has been paid to heterophasic thermoplastic ethylene-propylene copolymers. The present study was carried out to examine changes in the crystallinity of heterophasic ethylene-propylene copolymers upon UV irradiation and compare the results with a crystalline homopolymer of propylene.

\section{EXPERIMENTAL}

Commercial isotactic polypropylene (i-PP, Koylene S 3030, MI = 3.0, Indian Petrochemical Corporation, Baroda) and ethylene-propylene copolymers [E-P copolymer] (EPQ 30R, $\mathrm{MI}=0.6-0.9$, and $\mathrm{EPF} 30 \mathrm{R}, \mathrm{MI}=13.0$, Himont, Italia) were used.

\section{Purification and Fractionation}

The pellets were dissolved in refluxing xylene under $\mathrm{N}_{2}$ atmosphere. The solution was filtered and the polymer was precipitated with methanol, and dried at $50^{\circ} \mathrm{C}$ in vacuo. For fractionation, a hot solution of the copolymer was cooled to room temperature. After

\footnotetext{
† N.C.L. Communication No. 5257.
} 
filtration the seperated polymer was dried in vacuo at $50^{\circ} \mathrm{C}$ (fraction $\mathrm{A}$ ). The xylene soluble material was isolated by adding acetone and filtered the separated solid (fraction B). A small amount of xylene and acetone soluble polymer was isolated by the total evaporation of the filtrate (fraction C).

\section{Sample Preparation}

Thin films (thickness $=\sim 120 \mu \mathrm{m}$ ) of neat copolymers and fraction $\mathrm{A}$ were prepared by a preheated carver press at $170^{\circ} \mathrm{C}$ at $150 \mathrm{~kg} \mathrm{~cm}^{-2}$ platen pressure for 30 seconds. The films were quenched in the press. Films of fraction B were obtained by casting $0.5 \mathrm{wt} \%$ polymer solution in xylene. Residual solvents were removed by heating at $50^{\circ} \mathrm{C}$ under vacuo.

\section{UV Irradiation}

Films were irradiated in the photo-irradiation chamber (SEPAP 12.24 Le Materiel Physico Chimique, Neuilly, France) at $55^{\circ} \mathrm{C}$. The unit consist of four $400 \mathrm{w}$ 'medium pressure' mercury sources filtered by a pyrex envelop supplying radiation longer than 300 $\mathrm{nm}$. These sources were located at the four corners of a square chamber $(50 \times 50 \mathrm{~cm})$. The inside walls of the chamber were made up of high reflectant aluminium. Twenty four samples were irradiated on a rotating support located at the centre. The surface temperature can be measured by a thermocouple in close contact with the sample. Two fans on the walls of the chamber afford a regulation of the sample temperature $\left( \pm 2^{\circ} \mathrm{C}\right.$ between 40 $\left.80^{\circ} \mathrm{C}\right)$.

\section{Analysis}

${ }^{13} \mathrm{C}$ NMR spectra were recorded on a Bruker MSL 300 spectrometer of $75.48 \mathrm{MHz}$ with broad band decoupling. Spectra were recorded at $120^{\circ} \mathrm{C}$ using 1,2-dichlorobenzene as a solvent. The composition and monomer sequence distribution was determined by the method of Randall. ${ }^{8}$ Ethylene content in the copolymer film was cross-checked by Nicolet
60 SXB FT-IR spectroscopy at $4323 \mathrm{~cm}^{-1}$ and the area under the methylene curve $(760$ $\left.790 \mathrm{~cm}^{-1}\right)$. Mol\% ethylene in copolymer was calculated using the expression, $\mathrm{C}_{2} \mathrm{~mol} \%=$ $A / A_{\mathrm{S}} F \times 28$, where $A=$ area of methylene sequence band with respect to base line. $A_{\mathrm{S}}=$ absorbance of $4323 \mathrm{~cm}^{-1}$ band and $F=$ angular coefficient of the calibrating straight line.

\section{Viscosity}

Decalin was purified by percolation through a 100-200 mesh silica gel which removes impurities. To inhibit oxidation $0.1 \mathrm{wt} \%$ 2,6-di-tert-butyl-p-cresol was added to redistilled decalin. Intrinsic viscosity was measured by successive dilutions of only one decalin solution (concn. $=0.2 \mathrm{wt} \%$ ) at $135 \pm 0.1{ }^{\circ} \mathrm{C}$. Error due to expansion of the flask at $135^{\circ} \mathrm{C}$ was negligible since a preheated flask and pipette $\left(140^{\circ} \mathrm{C}\right)$ was used to mix the solvent into an Ubbelohde viscometer.

\section{Crystallinity Measurement}

Calorimetry was made by a Perkin Elmer DSC-2 between $25-250^{\circ} \mathrm{C}$ at $10^{\circ} \mathrm{C} \mathrm{min}^{-1}$ in nitrogen flux. Wide angle X-ray diffraction pattern. was recorded in the range of $2 \theta=5-50^{\circ}$ from a Phillips PW 1730 X-ray generator. Crystallinity was calculated by the expression $^{9} \quad X_{\mathrm{c}}=I_{\mathrm{c}} /\left(I_{\mathrm{c}}+I_{\mathrm{a}}\right)$, where $I_{\mathrm{c}}$ and $I_{\mathrm{a}}$ represent the integrated intensity of the crystalline and amorphous phases, respectively.

\section{RESULTS AND DISCUSSION}

\section{Characterization of the Samples}

Ethylene content determined by FT-IR and weight fraction of the xylene insoluble, xylene soluble-acetone insoluble and xylene solubleacetone soluble fractions of the samples are shown in Table I. Heterophasic E-P copolymers consisting of polypropylene (PP) and polyethylene (PE) phases was also accompanied by an amorphous E-P elastomer (EPR) phase which was extracted. E-P copolymers 
Table I. Fractionation and Ethylene content of copolymer samples

\begin{tabular}{|c|c|c|c|c|c|c|c|c|}
\hline $\begin{array}{c}\text { Sample } \\
\text { No. }\end{array}$ & $\begin{array}{c}\text { Grade } \\
\text { designation }\end{array}$ & $\begin{array}{c}\text { Xylene } \\
\text { insoluble } \\
\text { wt } \% \\
\text { Fraction-A }\end{array}$ & $\begin{array}{l}\text { Ethylene } \\
\text { content }^{\mathrm{a}} \\
\text { mol\% in } \\
\text { Fraction-A }\end{array}$ & $\begin{array}{c}\text { Xylene } \\
\text { soluble } \\
\text { wt\% } \% \\
\text { Fraction-B }\end{array}$ & $\begin{array}{l}\text { Ethylene } \\
\text { content }^{\mathrm{a} /} \\
\text { mol\% in }^{\circ} \text { in } \\
\text { Fraction-B }\end{array}$ & $\begin{array}{c}\text { Acetone } \\
\text { soluble } \\
\text { wt } \% \\
\text { Fraction-C }\end{array}$ & $\begin{array}{c}\text { Purified } \\
\text { (methanol } \\
\text { precipitated) } \\
\text { wt } \%\end{array}$ & $\begin{array}{c}\text { Ethylene } \\
\text { content/ } \\
\text { mol } \%\end{array}$ \\
\hline I & $\begin{array}{l}\text { i-PP } \\
\text { S } 3030\end{array}$ & 94.8 & - & 3.3 & - & 2.0 & 99.4 & - \\
\hline II & EPQ 30R & 85.9 & 7.7 & 11.9 & 40.9 & 2.2 & 95.2 & 15.1 \\
\hline III & EPF $30 R$ & 87.3 & 6.2 & 7.0 & 55.7 & 2.3 & 99.2 & 12.0 \\
\hline
\end{tabular}

a Determined by FT-IR Spectroscopy.

Table II. Copolymer composition and sequence distribution from ${ }^{13} \mathrm{C} N M R$ data ${ }^{\mathrm{a}}$

\begin{tabular}{|c|c|c|c|c|c|c|c|}
\hline & & \multicolumn{6}{|c|}{ Copolymer composition } \\
\hline & & II & $\mathrm{II}_{\mathbf{A}}$ & $\mathrm{II}_{\mathrm{B}}$ & III & $\mathrm{III}_{\mathrm{A}}$ & $\mathrm{III}_{\mathrm{B}}$ \\
\hline \multirow{2}{*}{\multicolumn{2}{|c|}{$\begin{array}{l}\text { Ethylene/mol\% } \\
\text { Propylene/mol\% }\end{array}$}} & 15.95 & 8.06 & 47.44 & 12.24 & 6.87 & 58.12 \\
\hline & & 84.05 & 91.94 & 52.56 & 87.76 & 93.13 & 41.88 \\
\hline & & \multicolumn{6}{|c|}{ Sequence distribution } \\
\hline & & II & $\mathrm{II}_{\mathrm{A}}$ & $\mathbf{I I}_{\mathbf{B}}$ & III & $\mathrm{III}_{\mathrm{A}}$ & $\mathrm{III}_{\mathbf{B}}$ \\
\hline & $\mathbf{P}$ & 84 & 92 & 52 & 88 & 94 & 42 \\
\hline \multirow{2}{*}{ Monads } & $\mathrm{E}$ & 16 & 8 & 48 & 12 & 6 & 58 \\
\hline & PP & 88 & 93 & 30 & 73 & 88 & 26 \\
\hline \multirow[t]{5}{*}{ Diads } & PE & 2 & 1 & 28 & 9 & 3 & 35 \\
\hline & $\mathrm{EE}$ & 10 & 6 & 42 & 18 & 9 & 39 \\
\hline & PPP & 85 & 93 & 24 & 87 & 93 & 16 \\
\hline & PPE & 2 & 0 & 15 & 2 & 1 & 17 \\
\hline & EPE & 2 & 0 & 11 & 1 & 0 & 11 \\
\hline \multirow[t]{3}{*}{ Triads } & PEP & 1 & 0 & 9 & 2 & 0 & 10 \\
\hline & EEP & 3 & 1 & 19 & 2 & 1 & 23 \\
\hline & EEE & 7 & 6 & 22 & 6 & 5 & 23 \\
\hline
\end{tabular}

a $\mathbf{P}$, propylene; E, ethylene.

and their fractions were characterized by $[\eta]$, DSC, and X-ray. Ethylene content and triad sequence distribution of each sample was obtained by ${ }^{13} \mathrm{C}$ NMR analysis (Table II). PPP and EEE express segments consisting of three consecutively linked units of propylene and ethylene, respectively. The values of one PPP-EEE has been used as an indication of the randomness of ethylene-propylene sequences where diads and triads represent long segments of ethylene and propylene. Fraction
$\mathrm{II}_{\mathrm{A}}$ and $\mathrm{III}_{\mathrm{A}}$ contain $\mathrm{PP}$ as the main component and the values of 1-PPP-EEE, 93-6 and 93-5, respectively, indicate the presence of PEP components in the fractions. The frequency of randomness in E-P copolymers gradually increased from III $_{A}$ to III $_{B}$ because the frequency of the PPP sequences decreased.

The decrease of $[\eta]$ of the samples (i-PP, i-PP fraction A, EPQ 30R, EPQ 30R-fraction A, EPQ 30R-fraction B, EPF 30R, EPF 30R-fraction A, EPF 30R-fraction-B: I, $I_{A}, I I$, 


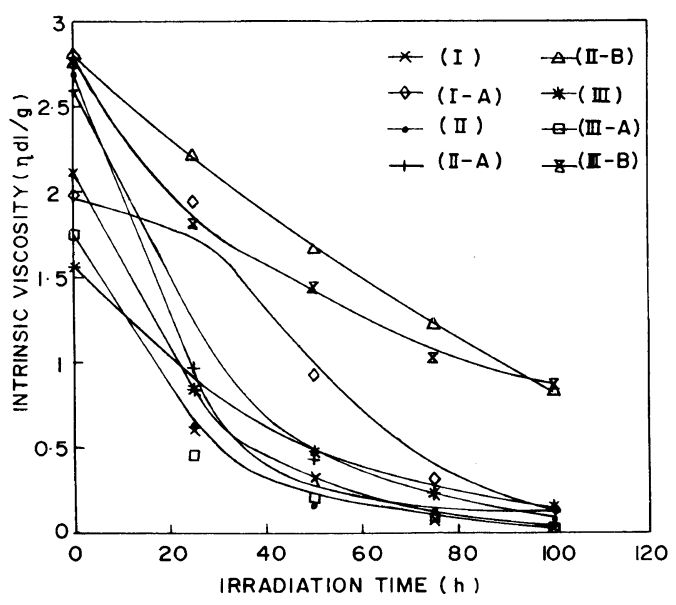

Figure 1. Viscosity changes at various times Polychromatic irradiated E-P copolymer samples.

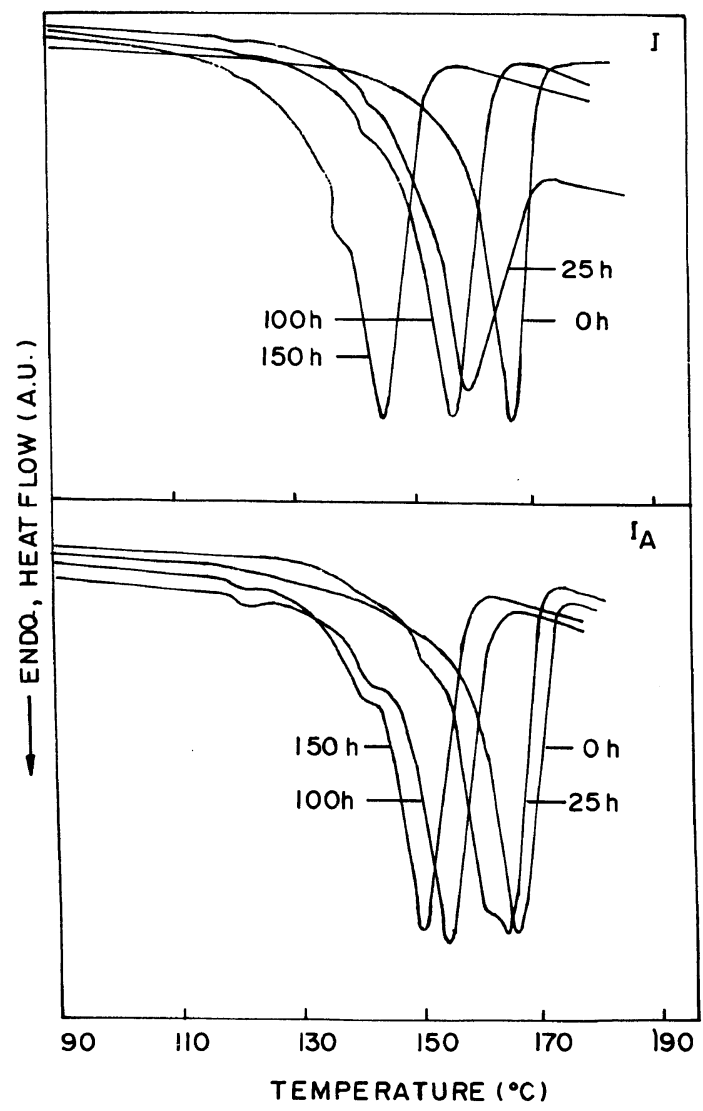

Figure 2. Heating DSC curves at various times Polychromatic irradiated $\mathbf{I}$ and $\mathbf{I}_{\mathrm{A}}$ films.

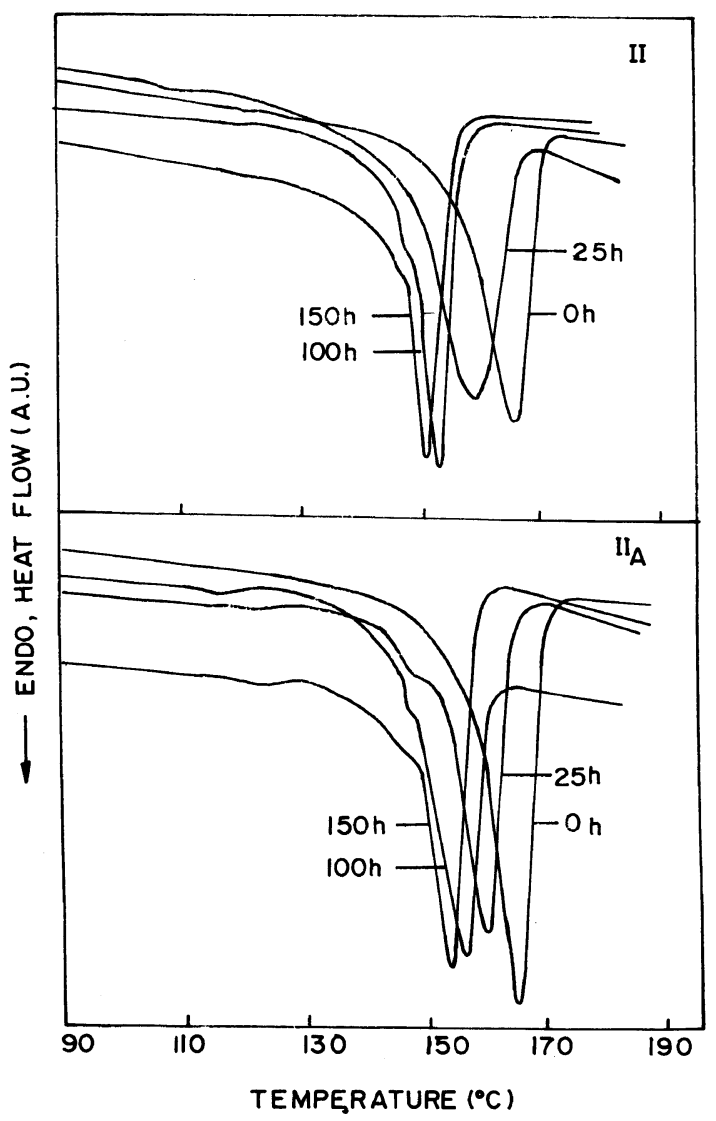

Figure 3. Heating DSC curves at various times Polychromatic irradiated $\mathrm{II}$ and $\mathrm{II}_{\mathrm{A}}$ films.

$\mathrm{II}_{\mathrm{A}}, \mathrm{II}_{\mathrm{B}}, \mathrm{III}, \mathrm{III}_{\mathrm{A}}$, and $\mathrm{III}_{\mathrm{B}}$, respectively) are shown in Figure 1. Ethylene inclusion ${ }^{10}$ has an effect on the molecular weight of the pure PP matrix. Therefore, $[\eta]$ of $\mathrm{II}_{\mathrm{B}}$ and $\mathrm{III}_{\mathrm{B}}$ are higher but $\mathrm{III}_{B}$ is lower $[\eta]$ than $\mathrm{II}_{B}$ which could be due to nucleation since partially ordered domains lead to additional volume contraction with further decrease in $[\eta]$. Canadia et al. ${ }^{11}$ reported that intermolecular ordering becomes more prominant in $\mathrm{E}-\mathrm{P}$ copolymers with higher ethylene content with further decrease in $[\eta]$ of $\mathrm{III}_{\mathrm{B}}$.

DSC melting endotherms for samples $\mathrm{I}, \mathrm{I}_{\mathrm{A}}$, II, and $\mathrm{II}_{\mathrm{A}}$, are shown in Figures 2 and 3. Being highly amorphous in nature, $\mathrm{II}_{\mathbf{B}}$ and $\mathrm{III}_{\mathbf{B}}$ did not show any endotherm. The resulting peak melting point $\left(T_{\mathrm{m}}\right)$, heat of fusion $\left(\Delta H_{\mathrm{f}}\right)$, and 
Table III. Percent crystallinity $\left(X_{\mathrm{C}} \%\right)$, enthalpy of fusion $\left(\Delta H_{\mathrm{f}}\right)$, entropy of fusion of $100 \%$ crystalline sample $\left(\Delta S_{\mathrm{f}}\right)$, melting temperature $\left(T_{\mathrm{m}}\right)$, crystallization temperature $\left(T_{\text {cryst }}\right)$, heat of crystallization $\left(\Delta H_{\text {cryst }}\right)$, and full width at half maximum $\left(\Delta T_{\mathrm{c}}\right)$ of E-P copolymers and i-PP homopolymers upon irradiation

\begin{tabular}{|c|c|c|c|c|c|c|c|c|c|}
\hline \multirow{2}{*}{$\begin{array}{l}\text { Sample } \\
\text { code }\end{array}$} & \multirow{2}{*}{$\begin{array}{l}\text { Irradiation } \\
\text { time } / \mathrm{h}\end{array}$} & \multirow{2}{*}{$X_{\mathrm{c}} \%$} & \multirow{2}{*}{$\frac{\Delta H_{\mathrm{f}}}{\mathrm{Jg}^{-1}}$} & \multirow{2}{*}{$\frac{T_{\mathrm{m}}}{\mathrm{K}}$} & \multirow{2}{*}{$\frac{\Delta S_{\mathrm{f}}}{\mathrm{Jg}^{-1} \mathrm{~K}^{-1}}$} & \multirow{2}{*}{$\frac{T_{\text {cryst }}}{\mathrm{K}}$} & \multirow{2}{*}{$\frac{\Delta H_{\text {cryst }}}{\mathrm{Jg}^{-1}}$} & \multirow{2}{*}{$\frac{\Delta T_{\mathrm{c}}}{\mathrm{cm}}$} & \multirow{2}{*}{$\frac{T_{\text {onset }}-T_{\mathrm{c}}}{\mathrm{K}}$} \\
\hline & & & & & & & & & \\
\hline \multirow[t]{6}{*}{ I } & 0 & 66.9 & 109.1 & 439.5 & 0.36 & 387.0 & 93.9 & 0.60 & 278.0 \\
\hline & 25 & 50.5 & 82.4 & 430.3 & 0.29 & 389.1 & 94.9 & 0.85 & 277.4 \\
\hline & 75 & 61.5 & 100.3 & 428.3 & 0.23 & 387.1 & 94.0 & 0.85 & 277.3 \\
\hline & 100 & 67.1 & 109.3 & 433.5 & 0.33 & 386.4 & 94.6 & 0.85 & 277.5 \\
\hline & 125 & 63.9 & 104.1 & 422.8 & 0.30 & 385.2 & 84.7 & 1.00 & 277.1 \\
\hline & 150 & 52.9 & 86.3 & 413.8 & 0.27 & 384.2 & 85.9 & - & 277.0 \\
\hline \multirow[t]{6}{*}{$\mathbf{I}_{\mathbf{A}}$} & 0 & 53.2 & 86.7 & 438.7 & 0.29 & 387.6 & 96.0 & 0.90 & 279.1 \\
\hline & 25 & 52.2 & 85.1 & 436.9 & 0.30 & 388.3 & 95.1 & 0.95 & 278.9 \\
\hline & 75 & 56.1 & 91.4 & 429.4 & 0.28 & 387.7 & 94.9 & 0.80 & 277.4 \\
\hline & 100 & 59.8 & 97.5 & 429.1 & 0.27 & 383.5 & 89.9 & 1.00 & 278.1 \\
\hline & 125 & 64.0 & 104.3 & 424.7 & 0.31 & 386.4 & 87.3 & 0.90 & 276.6 \\
\hline & 150 & 68.5 & 111.6 & 423.7 & 0.26 & 385.3 & 83.2 & - & 276.8 \\
\hline \multirow[t]{6}{*}{ II } & 0 & 51.2 & 83.5 & 438.6 & 0.33 & 385.4 & 73.1 & 0.65 & 278.8 \\
\hline & 25 & 42.6 & 69.5 & 430.0 & 0.26 & 388.1 & 78.1 & 0.90 & 277.5 \\
\hline & 75 & 45.7 & 74.6 & 424.8 & 0.27 & 386.0 & 73.6 & 0.80 & 277.8 \\
\hline & 100 & 46.5 & 75.7 & 424.2 & 0.27 & 383.7 & 75.6 & 0.80 & 278.3 \\
\hline & 125 & 48.2 & 78.6 & 422.2 & 0.27 & 382.9 & 68.2 & 1.00 & 276.7 \\
\hline & 150 & 51.7 & 84.3 & 422.6 & 0.31 & 380.7 & 69.2 & - & 276.3 \\
\hline \multirow[t]{6}{*}{$\mathrm{II}_{\mathrm{A}}$} & 0 & 61.6 & 100.3 & 439.7 & 0.36 & 384.8 & 88.4 & 0.65 & 278.2 \\
\hline & 25 & 50.0 & 77.9 & 431.0 & 0.29 & 389.7 & 86.4 & 0.75 & 277.6 \\
\hline & 75 & 58.6 & 95.5 & 431.2 & 0.32 & 383.0 & 86.7 & 0.85 & 278.6 \\
\hline & 100 & 62.9 & 102.5 & 428.1 & 0.34 & 382.6 & 84.1 & 0.80 & 278.7 \\
\hline & 125 & 63.6 & 103.7 & 427.8 & 0.34 & 383.4 & 83.1 & 0.85 & 276.9 \\
\hline & 150 & 63.9 & 104.1 & 424.3 & 0.35 & 381.5 & 80.1 & - & 276.2 \\
\hline \multirow[t]{6}{*}{ III } & 0 & 60.2 & 106.2 & 441.4 & 0.37 & 387.9 & 99.8 & 0.60 & 278.8 \\
\hline & 25 & 50.3 & 81.9 & 432.7 & 0.28 & 390.7 & 90.8 & 0.60 & 277.4 \\
\hline & 75 & 57.1 & 93.1 & 427.8 & 0.31 & 385.6 & 83.7 & 0.60 & 277.1 \\
\hline & 100 & 58.3 & 95.1 & 427.6 & 0.31 & 385.2 & 82.1 & 0.70 & 276.9 \\
\hline & 125 & 59.6 & 97.2 & 426.6 & 0.31 & 385.7 & 83.2 & 0.55 & 276.7 \\
\hline & 150 & 64.3 & 104.8 & 426.5 & 0.34 & 385.0 & 82.4 & - & 276.0 \\
\hline \multirow[t]{6}{*}{$\mathrm{III}_{\mathrm{A}}$} & 0 & 63.5 & 101.9 & 442.8 & 0.34 & 388.3 & 94.3 & 0.70 & 278.5 \\
\hline & 25 & 53.7 & 87.5 & 429.7 & 0.30 & 389.7 & 96.7 & 0.90 & 277.4 \\
\hline & 75 & 63.2 & 103.0 & 427.1 & 0.33 & 386.0 & 93.6 & 0.80 & 277.1 \\
\hline & 100 & 66.9 & 109.1 & 423.9 & 0.34 & 385.9 & 89.8 & 0.80 & 277.1 \\
\hline & 125 & 66.8 & 106.8 & 424.5 & 0.32 & 384.3 & 83.5 & 1.00 & 276.7 \\
\hline & 150 & 68.6 & 111.9 & 424.4 & 0.34 & 382.9 & 82.7 & - & 276.5 \\
\hline
\end{tabular}

percent crystallinity $\left(X_{\mathrm{c}}\right)$ derived from these thermograms are given in Table III. The peak maximum for the melting endotherm was considered the melting point $\left(T_{\mathrm{m}}\right)$. The area of the melting endotherm was calculated and reported as $\Delta H_{\mathrm{f}}$. Percent crystallinity was calculated assuming the heat of fusion ${ }^{12}$ of $100 \%$ crystalline polypropylene as $209 \mathrm{~J} \mathrm{~g}^{-1}$.
The copoymer containing higher ethylene content (sample II and III) showed a lower $T_{\mathrm{m}}$ and $\Delta H_{\mathrm{f}}$. Crystallinity also decreased with higher ethylene content. This is expected since ethylene occurs in the form of an amorphous ethylene-propylene block segments in the copolymer. The crystallinity and $T_{\mathrm{m}}$ of $\mathrm{II}_{\mathrm{A}}$ and III $_{A}$ are higher since upon extraction, EPR 


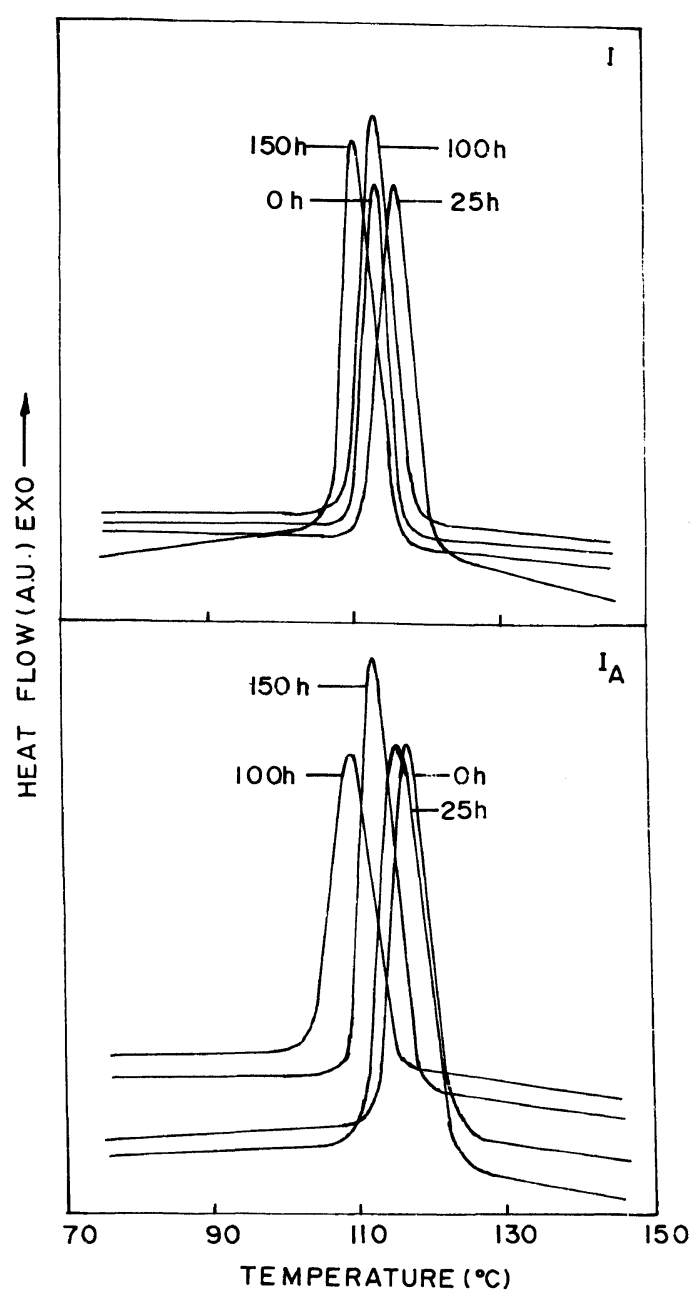

Figure 4. DSC cooling exotherm at various times Polychromatic irradiated $\mathrm{I}$ and $\mathrm{I}_{\mathrm{A}}$ films.

portion is removed.

Crystallization peaks were also read off from the cooling curves (Figures 4 and 5). All the samples showed only one sharp crystallization exotherm during the cooling cycles. The crystallization temperature $\left(T_{\mathrm{c}}\right)$ and heat of crystallization $\left(\Delta H_{\text {cryst }}\right)$ were evaluated from the cooling curves and are also given in Table III. The difference between $T_{\mathrm{m}}$ and $T_{\mathrm{c}}$ for copolymer before and after irradiation was $\sim 53$ and $42 \mathrm{~K}$ which is similar to the value observed in homopolymer, viz. 52.5 and $43 \mathrm{~K}$. This implies that the observed crystallization

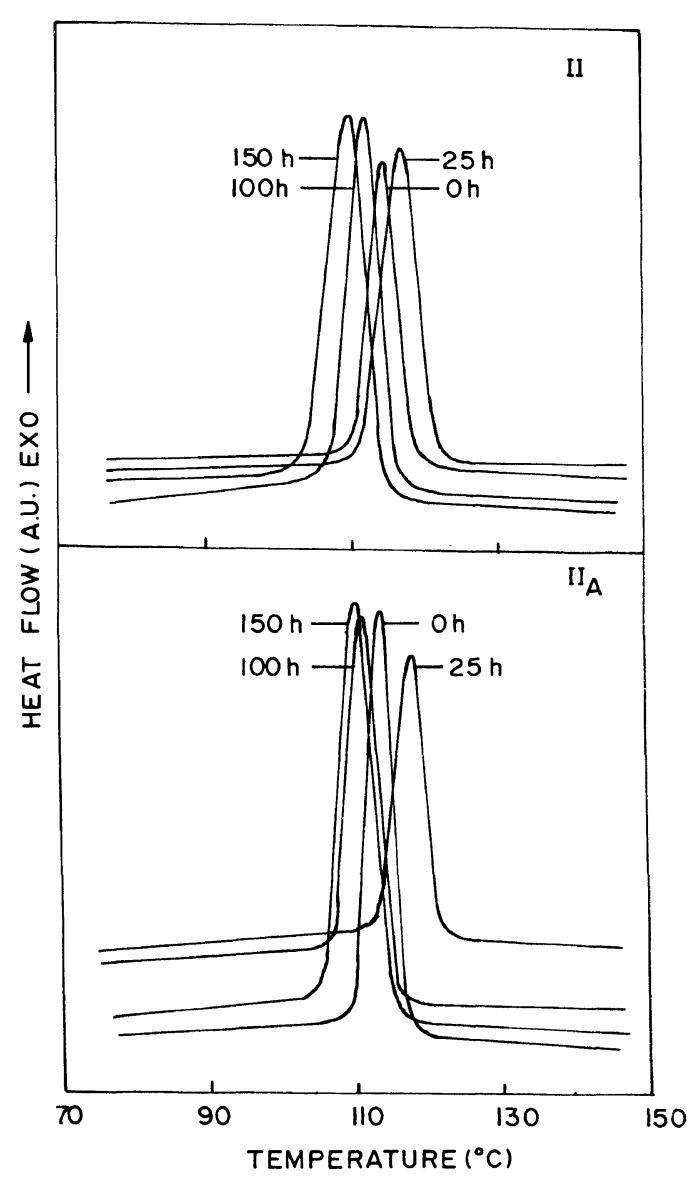

Figure 5. DSC cooling exotherm at various times Polychromatic irradiated $\mathrm{II}$ and $\mathrm{II}_{\mathrm{A}}$ films.

in copolymer is predominantly due to the presence of propylene homopolymer blocks.

X-Ray diffraction studies of PP and E-P copolymers (II, $\mathrm{II}_{\mathrm{A}}, \mathrm{III}$, and $\mathrm{III}_{\mathrm{A}}$ ) showed peaks at $2 \theta$ of $14,17,18.5$, and $21.3^{\circ}$ corresponding to the (110), (040), (130), and (111) diffraction peaks (Figures 6 and 7). These X-ray patterns exhibited peaks of the stable $\alpha$-form of isotactic polypropylene..$^{13-15}$ This was confirmed from DSC endotherms also where $T_{\mathrm{m}}$ of $\mathrm{PE}$ ( $\sim 122^{\circ} \mathrm{C}$ and $\beta$-form of $\mathrm{PP}\left(\sim 150^{\circ} \mathrm{C}\right)$ were absent altogether. ${ }^{16-18}$ The presence of these characteristic crystalline peaks of $\mathrm{I}, \mathrm{I}_{\mathrm{A}}, \mathrm{II}, \mathrm{II}_{\mathrm{A}}$, III, and III $_{A}$ clearly indicates that the crystal structure of i-PP remains unchanged up to 


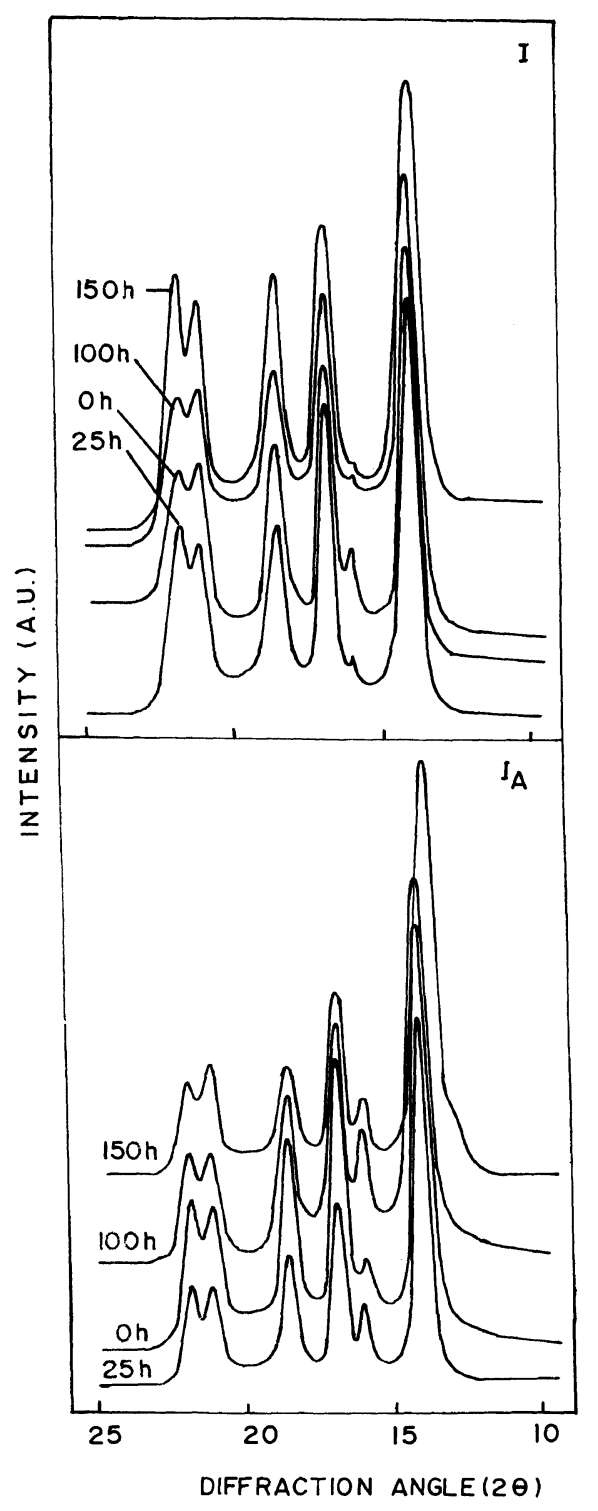

Figure 6. Variations of X-ray diffraction pattern at various times Polychromatic irradiated $I$ and $I_{A}$ films.

$<16 \mathrm{~mol} \%$ of ethylene. The $d$-spacings (inter planar distance) were found to be $6.38,5.24$, 4.82 , and $4.13 \mathrm{~A}^{\circ}$, respectively. No significant change in intensity was observed with increasing concentration of ethylene.

No well resolved peak was observed in X-ray diffraction for $\mathrm{II}_{B}$ and $\mathrm{III}_{\mathrm{B}}$ due to their completely amorphous nature. The values of

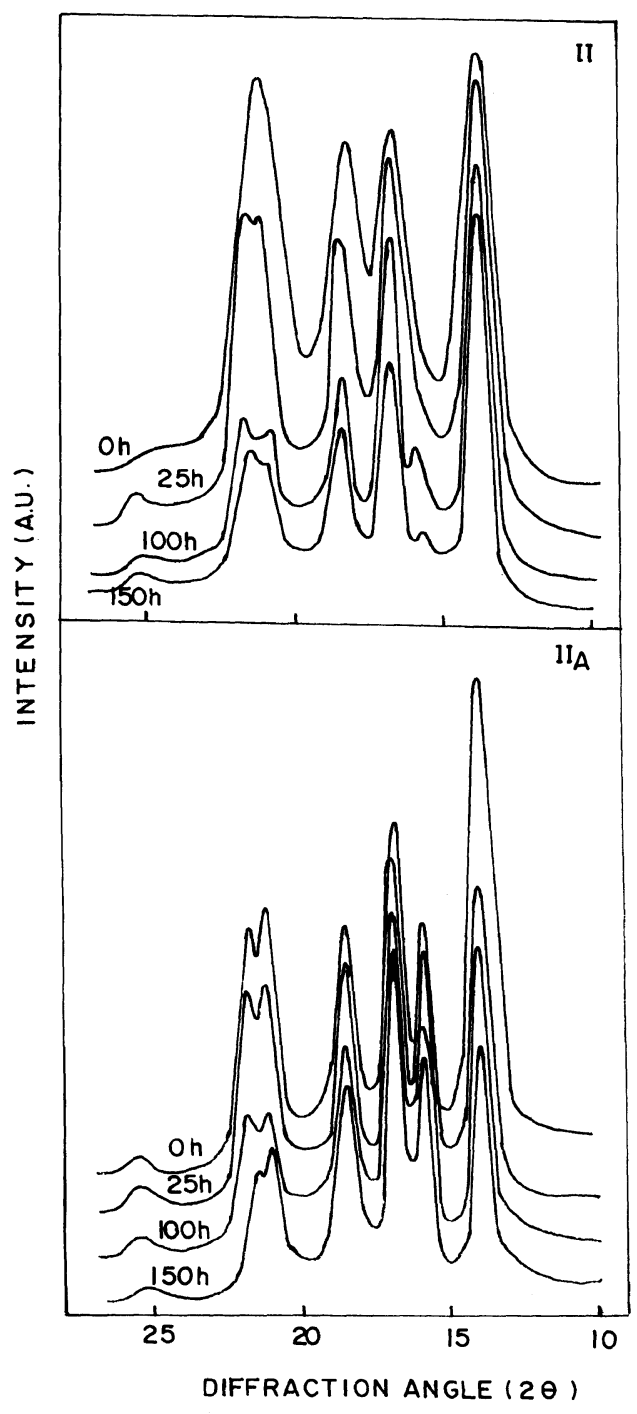

Figure 7. Variations of X-ray diffraction pattern at various times Polychromatic irradiated $\mathrm{II}_{\text {and }} \mathrm{II}_{\mathrm{A}}$ films.

crystallinity derived from WAXS diffractograms for samples $\mathrm{I}_{,} \mathrm{I}_{\mathbf{A}}, \mathrm{II}, \mathrm{II}_{\mathbf{A}}, \mathrm{III}$, and $\mathrm{III}_{\mathbf{A}}$ are shown in Table IV.

\section{Effect of UV Irradiations}

The photo-oxidation of E-P copolymers at $55^{\circ} \mathrm{C}$ in air affected both the molecular structure of the chains and crystallinity of the solid sample. 
Table IV. WAXS percent crystallinity $\left(X_{\mathrm{c}} \%\right)$ of E-P copolymers and i-PP homopolymers as a function of irradiation time

\begin{tabular}{lccccccc}
\hline & \multicolumn{7}{c}{ Percent crystallinity/ $X_{\mathbf{c}} \%$} \\
\cline { 2 - 8 } $\begin{array}{c}\text { Sample } \\
\text { code }\end{array}$ & \multicolumn{7}{c}{ Irradiation time $/ \mathrm{h}$} \\
\cline { 2 - 8 } & 0 & 25 & 50 & 75 & 100 & 125 & 150 \\
\hline II & 68.9 & 67.2 & 69.7 & 74.1 & 76.5 & 81.3 & 77.3 \\
I & 69.5 & 66.1 & 68.2 & 70.4 & 72.6 & 80.1 & 74.2 \\
II & 59.8 & 57.2 & 63.5 & 65.1 & 66.3 & 69.3 & 65.3 \\
II & 63.5 & 62.6 & 65.3 & 68.4 & 69.8 & 72.6 & 70.6 \\
III & 67.2 & 66.4 & 69.9 & 70.2 & 72.5 & 74.5 & 71.5 \\
III $_{\text {A }}$ & 68.1 & 67.3 & 72.1 & 74.3 & 76.5 & 78.3 & 76.9 \\
\hline
\end{tabular}

\section{Changes in $[\eta]$}

$[\eta]$ of all the samples decreased with irradiation time (Figure 1) and higher [ $\eta]$ copolymer (EPQ 30R) showed maximum decrease. Chain-scission occurs via photooxidation initiated by photolysis of trace amounts of impurities formed in the processing. The initial decrease is due to scission of weak links but contrary to Jellinek and Flagsman, ${ }^{19}$ we did not observe crosslinking in the present system as [ $\eta]$ did not increase. Regardless of the long irradiation time, the films remained completely soluble in decalin indicating that no appreciable crosslinking had taken place.

\section{Changes in DSC Thermograms}

DSC melting endotherms and crystallization peaks for unirradiated and irradiated films are shown in Figures 2-5. A small decrease in $T_{\mathrm{m}}$ is observed with irradiation time. It is well known that the thermodynamic $T_{\mathrm{m}}$ of semicrystalline polymers decreases ${ }^{20,21}$ and the number of defects increases as the molecular weight decreases. According to Kocsis et al. ${ }^{22}$ the shifting of $T_{\mathrm{m}}$ to lower temperature on irradiation can be correlated to the formation of smaller spherulity ${ }^{23}$ thereby causing higher crystallinity. The minor decrease in spherulite size with exposure is probably due to crystal perfection by irradiation. $\Delta H_{\mathrm{f}}$ of the exposed samples decreases up to $25 \mathrm{~h}$ irradiation and thereafter increases. Change in $\Delta H_{\mathrm{f}}$ suggests that molecular changes in the crystalline regions occur. The width of crystallization exotherm $\left(\Delta T_{\mathrm{c}}\right)$ was found to increase on irradiation which means that irradiation facilitates crystallization. As expected, the values of $X_{c}$ decreases initially $(25 \mathrm{~h})$ with irradiation time (Table III). The initial decrease of $X_{\mathrm{c}}$ is due to degradation/fragmentation of macrochains. There is a slow decrease between $T_{\text {onset }}-T_{\mathrm{c}}$ on irradiation. Such a decrease in $T_{\text {onset }}-T_{\mathrm{c}}$ can be attributed to increase in the rate of crystallization. The increase in rate of crystallization with irradiation may be due to better alignment in the crystalline lattice.

\section{Changes in X-Ray Diffraction}

WAXS diffractograms of unirradiated and irradiated samples are illustrated in Figures 6 and 7. The irradiation process significantly changes the intensity of $14^{\circ}, 17^{\circ}, 18.5^{\circ}$, and $21.3^{\circ}(2 \theta)$ reflections in all the samples. Upon irradiation, a structural transition from a disordered to ordered state was observed as is evident by crystallinity increase (Table IV). We observed two different phases on irradiation in our experimental results. In all cases the unirradiated crystal lattice is characteristic the $\alpha$-modification of polypropylene. ${ }^{13-15}$ There was a gain in the (110) peak intensity while the (040) peak declined and developed a shoulder at $2 \theta=15.2^{\circ}$, indicating the formation of 
additional $\beta$-phase of polypropylene. The loss of $\alpha$-form intensity (040) is not equal to the simultaneous gain of $\beta$-form intensity (300). This means that the $\alpha$-form changes partially to the $\beta$-form and simultaneously itself is recrystallized. Also, the $\beta$-phase formation has been confirmed by DSC results, on irradiation, samples show a sharp endotherm corresponding to the melting of the most perfect $\alpha$-modification $\left(T_{\mathrm{m}}=166^{\circ} \mathrm{C}\right)$ together with two shoulders at lower temperatures belonging to the $\beta$-phase. The unit cells of the $\beta$-form are packed less densely ${ }^{24}$ than those of the $\alpha$-form. Therefore, the crystallization of the molecular chains is promoted in the $\beta$-modification.

There is a difference in crystallinity from DSC and X-ray diffractograms. The value of $X_{\mathrm{c}}$ depends very much on the method and techinique of measurements. ${ }^{12}$ The lower values of $X_{\mathrm{c}}$ from DSC as compared to the $\mathrm{X}$-ray have been reported ${ }^{25}$ but the results of $\mathrm{X}$-ray measurements are in line with those of DSC measurements.

Oxidative degradation is promoted by the sample which induces both carbonyl formation and breaking of chains thereafter. ${ }^{26}[\eta]$ results also confirm this chain-scission. Tables III and IV show that $X_{\mathrm{c}}$ decreases initially and then there is continuous increase. The decrease in $X_{\mathrm{c}}$ up to $25 \mathrm{~h}$ is due to the accumulation of polar hydroxyl and hydroperoxide groups. For longer irradiation time (higher chain-scission), increase in $X_{\mathrm{c}}$ was observed. This means that lower molecular weight samples may crystallize faster because of less entanglement of the chains. Winslow and coworkers ${ }^{27,28}$ also explained $X_{\mathrm{c}}$ increase on the basis of disentanglement of segment in which chain-scission has occured along the macro-chain.

Irradiation probably engenders and identification of EPR at the interface between the dispersed phase of PE and PP matrix to cause an increase in the compatibilization of the macroscopic interfacial layers and contribute to increase in boding strength at the interface. Rosa et al. ${ }^{29}$ confirmed that components (low molecular weight PP, PE, and high molecular weights EPR) migrated from crystal regions into amorphous regions on the spherulite interface and become recrystallized. Recrystallization promotes the rejection of segments incapable of rearrangement in a crystal region and their recrystallization causes nucleation. On irradiation, segments transition from a disordered modification to a more ordered goes through recrystallization. ${ }^{29} \mathrm{Mo}-$ lecular mechanics calculations ${ }^{30}$ on model compounds also indicated that isolated ethylene units and EPR may be embedded the PP matrix. It appears that the amorphous material on irradiation makes domains of the dispersed PE phase smaller and more uniform and therefore $X_{\mathrm{c}}$ increases.

\section{CONCLUSIONS}

The copolymer with higher $[\eta]$ degrades rapidly irradiation. DSC thermograms show that the copolymer containing higher ethylene content ( $<16 \mathrm{~mol} \%$ ethylene) has lower $T_{\mathrm{m}}$. The crystallinity also decreases with higher ethylene content. The intensity in X-ray diffractograms decrease initially but again increases on longer irradiations. The change in $\Delta H_{\mathrm{f}}$ due to irradiation leads to the conclusion that for lower irradiation times $(25 \mathrm{~h})$, there is accumulation of hydroperoxides, which leads to chain-scission on longer irradiation causing regularity/nucleation in the present system. DSC and X-ray crystallinity values suggest that inclusion of amorphous EPR in i-PP and PE matrix results an increase in miscibility at the interface, thus causing increase in bonding strength with longer irradiation.

Acknowledgements. The authors thank the Indo-French Centre for the Promotion of Advanced Research (Centre Franco-Indien Pour la Promotion de la Recherche avance) for financial support of this work through a grant No: 308-6. RM is greatful to CSIR (India) for the award of a senior research fellowship. 


\section{REFERENCES}

1. S. Sivaram and R. P. Singh, Adv. Polym. Sci., 101, 169 (1991).

2. B. Ranby and J. F. Rabek, "Photodegradation, Photooxidation and Photostabilization of Polymers," Wiley, London, 1975.

3. D. J. Carlsson, D. W. Grattan, T. Suprunchuk, and D. M. Wiles, J. Appl. Polym. Sci., 22, 2217 (1978).

4. M. Fujiyama, H. Awaya, and K. Azuma, J. Polym. Sci., Polym. Lett. Ed., 18, 105 (1980).

5. R. P. Singh, J. Lacoste, R. Arnaud, and J. Lemaire, Polym. Degradation and Stability, 20, 49 (1988).

6. G. Gueskens and M. S. Kabamba, Polym. Degradation and Stability, 4, 69 (1982).

7. S. K. L. Li and J. E. Guillet, Macromolecules, 17, 111 (1984).

8. J. C. Randall, Macromolecules, 11, 33 (1978).

9. L. E. Alexander, "X-Ray Diffraction in Polymer Science," John Wiley and Sons, New York, N.Y., 1969, p 379.

10. J. K. Kocsis, L. Kiss, and V. N. Vuleznev, Polym. Commun., 25, 122 (1984).

11. F. De Canadia, R. Russo, and V. Vittoria, $J$. Macromol. Sci., B18, 257 (1980).

12. P. H. Herman and A. Weildinger, Macromol. Chem., 24, 44 (1961).

13. G. Natta and P. Corrdani, Nuvo Cimento, 15, 40 (1960).

14. A. Turner Jones, J. M. Aiglewood, and D. R. Becket, Macromol. Chem., 75, 134 (1964).

15. T. Hirosaka, Polym. J., 5, 111 (1973).
16. F. J. Padden and H. D. Keith, J. Appl. Phys., 30, 1479 (1959).

17. H. J. Leugering, Macromol. Chem., 109, 209 (1967).

18. G. Guerra, V. Petraccone, P. Corradini, C. De Rosa, R. Napolitano, and B. Pirrozi, J. Polym. Sci., Polym. Chem. Ed., 22, 1029 (1980).

19. H. H. G. Jellinek and F. Flagsman, J. Polym. Sci., 8, 711 (1970).

20. S. Z. D. Cheng and B. Wunderlich, J. Polym. Sci., Polym. Phys. Ed., 24, 595 (1986).

21. L. C. Lapez and G. L. Wilkes, Polymer, 29, 106 (1988).

22. J. K. Kocsis, A. Kallo, A. Szafner, G. Bodor, and Zs. Senyei, Polymer, 20, 37 (1979).

23.. M. Joshi, A. Mishra, and S. N. Maiti, J. Appl. Polym. Sci., 43, 311 (1991).

24. A. J. Lovinger, J. O. Chua, and C. C. Gryte, J. Polym. Sci., Polym. Phys. Ed., 15, 641 (1977).

25. C. E. Locke and D. R. Paul, Polym. Eng. Sci., 13, 308 (1973).

26. R. P. Singh, R. Mani, S. Sivaram, J. Lacoste, and D. Vaillant, J. Appl. Polym. Sci., 50, 1871 (1993).

27. F. H. Winslow, C. J. Aloisio, W. L. Hawkins, W. Matrgek, and S. Matsuoka, Chem. Ind. (London), 533 (1963).

28. F. H. Winslow, C. J. Aloisio, W. L. Hawkins, W. Matrgek, and S. Matsuoka, Chem. Ind. (London), 1465 (1963).

29. C. De Rosa, G. Guerra, R. Napolitano, V. Petraccone, and B. Pirrozi, Eur. Polym. J., 20, 937 (1984).

30. H. W. Starkweather, F. A. Van Catledge, and R. N. Mc Donald, Macromolecules, 15, 1600 (1982). 